\title{
Reacciones cutáneas inmediatas tardías a las vacunas para COVID-19: serie de cinco casos
}

\author{
Delayed immediate cutaneous reactions to COVID-19 vaccines: series of 5 cases
}

\author{
María Graciela Guzmán Perera, ${ }^{*}$ Marcela Saeb Lima ${ }^{\ddagger}$
} Citar como: Guzmán PMG, Saeb LM. Reacciones cutáneas inmediatas tardías a las vacunas para COVID-19: serie
de cinco casos. Acta Med Grupo Angeles. 2021; 19 (s1): s84-s90. https://dx.doi.org/10.35366/101035

\section{Resumen}

La pandemia por el virus SARS-CoV-2 se presentó como una enfermedad con gran morbimortalidad. Desde entonces se inició la carrera por la producción de una vacuna que previniera esta grave enfermedad y disminuyera la transmisión. Numerosos laboratorios se sumaron al esfuerzo y se desarrollaron múltiples plataformas: de ARNm, de vector viral, de subunidades proteicas virales, de ADN de virus vivos atenuados, etc. Sólo las dos primeras se han aplicado en las campañas de vacunación. Sin embargo, ninguna está exenta de provocar efectos secundarios que pueden ser inmediatos y/o tardíos. Estos efectos se explican por la liberación directa de histamina y péptidos vasoactivos mediados por IgE o por la activación de la vía alterna del complemento. Las lesiones tardías se relacionan con el depósito de complejos inmunes, daño vascular e infiltración por células inflamatorias en la piel en el sitio de la aplicación de la vacuna o a distancia, causando dermatitis subaguda o placas purpúricas. Hasta el momento se han vacunado en México mayores de 50 años, población que se encuentra bajo múltiples tratamientos y en quienes los metabolitos intermedios tóxicos, el efecto viral o el mecanismo de acción de los propios fármacos pueden actuar en conjunto para desarrollar cuadros clínicos complejos.

Palabras clave: Vacuna COVID-19, eritema, urticaria, angioedema, púrpura, vacuna ARNm.

\section{INTRODUCCIÓN}

Desde enero de 2020 a la fecha se han producido 161,824,992 casos de enfermedad COVID-19 causada por el virus SARS-CoV-2 y con ello 3'357.598 muertos, ${ }^{1}$

\section{Abstract}

The SARS-CoV-2 virus pandemic was presented as a disease with great morbidity and mortality. Since then, the race for the production of a vaccine that would prevent serious disease and reduce transmission began. Numerous laboratories joined the effort and multiple platforms were developed: mRNA, viral vector, viral protein subunits, DNA, live attenuated viruses, etcetera. Only the first two have been applied in vaccination campaigns. However, none is exempt from causing side effects, which can be immediate and/or late. These effects are explained by the direct release of histamine and vasoactive peptides mediated by $\lg E$ or activation of the alternative complement pathway. Late lesions are related to the deposition of immune complexes, vascular damage and infiltration by inflammatory cells in the skin, at the site of the vaccine application or remotely, causing subacute dermatitis or purpuric plaques. So far, over 50 years of age have been vaccinated in Mexico, a population that is under multiple treatments and in whom toxic intermediate metabolites, the viral effect or the mechanism of action of the drugs themselves can act together to develop complex clinical pictures

Keywords: Vaccine COVID-19, erythema, urticaria, angioedema, purpura, vaccine sRNAm.

\footnotetext{
* Dermatóloga del Hospital Ángeles Pedregal Ciudad de México. Ex-presidente de la Academia Mexicana de Dermatología, Fundación Mexicana para la Dermatología y Colegio Mexicano de Ciencias Dermatológicas.

‡ Dermatóloga y Dermatopatóloga del Hospital Ángeles Lomas, Centro Médico ABC e Instituto Nacional de Ciencias Médicas y de la Nutrición "Salvador Zubirán". Vicepresidente del Colegio Mexicano de Ciencias Dermatológicas.
}

dejando múltiples secuelas de la enfermedad e incalculables pérdidas a nivel económico. Es por eso que desde diciembre de 2020 la FDA (Food and Drug Administration) emitió una autorización para el desarrollo de emergencia de una vacuna contra el SARS-CoV-2. ${ }^{2}$ Se han dedicado

\section{Correspondencia:}

María Graciela Guzmán Perera

Correo electrónico: graceguzman07@gmail.com

www.medigraphic.com/actamedica 
enormes y rápidos esfuerzos para producir vacunas efectivas para frenar la transmisión del SARS-CoV-2 y disminuir la mortalidad. Existen varios grupos de vacunas: las de ARN (Pfizer, Moderna), las de vector viral en adenovirus (CanSino, AstraZeneca, Sinovac, Johnson \& Johnson), vacuna de subunidades proteicas (Novavax, Dynavax, Sanofi, algunas en fase II-III), otras de ADN y virus vivo atenuado que iniciando investigación. ${ }^{3}$

En México el programa de vacunación ha utilizado vacunas Pfizer, Astra Zéneca, CanSino, Sinovac, Sputnik y Novavax (algunas personas participan aún en fase II). Muchos mexicanos que han podido viajar a los Estados Unidos han recibido también Moderna y Johnson \& Johnson.

La preocupación real han sido los efectos secundarios. Todas las vacunas causan reacciones locales y sistémicas transitorias (dolor local, astenia, dolor corporal: muscular y articular, fiebre, cefalea), algunas han causado eventos neurológicos severos como síndrome de Gillian-Barré, mielitis transversas y fenómenos trombóticos a diversos niveles con trombocitopenia.

Las reacciones dermatológicas publicadas a la fecha son raras, incluyen cuadros de urticaria aguda y crónica con o sin anafilaxia, el denominado "brazo COVID" (placa de eritema en el sitio de la aplicación que aparece de dos a siete días después de la inoculación), casos de púrpura por vasculitis leucocitoclástica, placas de eccema, formación de granulomas en sitios previos de inyección de materiales de relleno con ácido hialurónico, entre otras. Se presentan cinco casos que implican a las vacunas: Moderna, ${ }^{2}$ Pfizer $^{2}$ y AstraZeneca. ${ }^{1}$

La fisiopatología de estas reacciones aún no se determina, aunque se sugiere que las proteínas virales y los vehículos pueden estar involucrados en la génesis de lesiones inmediatas mediante la liberación de histamina o de péptidos vasoactivos, ya sea por mecanismo inmunológico tipo I o por activación de la vía alterna del complemento. Los cuadros anafilácticos y urticarianos se han presentado con más frecuencia con vacunas de ARNm. ${ }^{4-7}$ Las lesiones tardías probablemente se producen en pacientes sensibilizados por contacto con los componentes de la fórmula, por daño directo de las proteínas virales a los vasos de pequeño calibre, depósito de complejos inmunes o mediadas por células. ${ }^{4,8}$ Las personas mayores de 50 años suelen ingerir múltiples medicamentos para el tratamiento de enfermedades crónicas, esto puede aumentar la gravedad de los cuadros clínicos sobre todo lesiones purpúricas secundarias a vasculitis leucocitoclástica ${ }^{9}$ o asociarse con fenómenos recall a la tormenta inmunológica durante la enfermedad COVID-19 previa a la vacunación. ${ }^{10}$
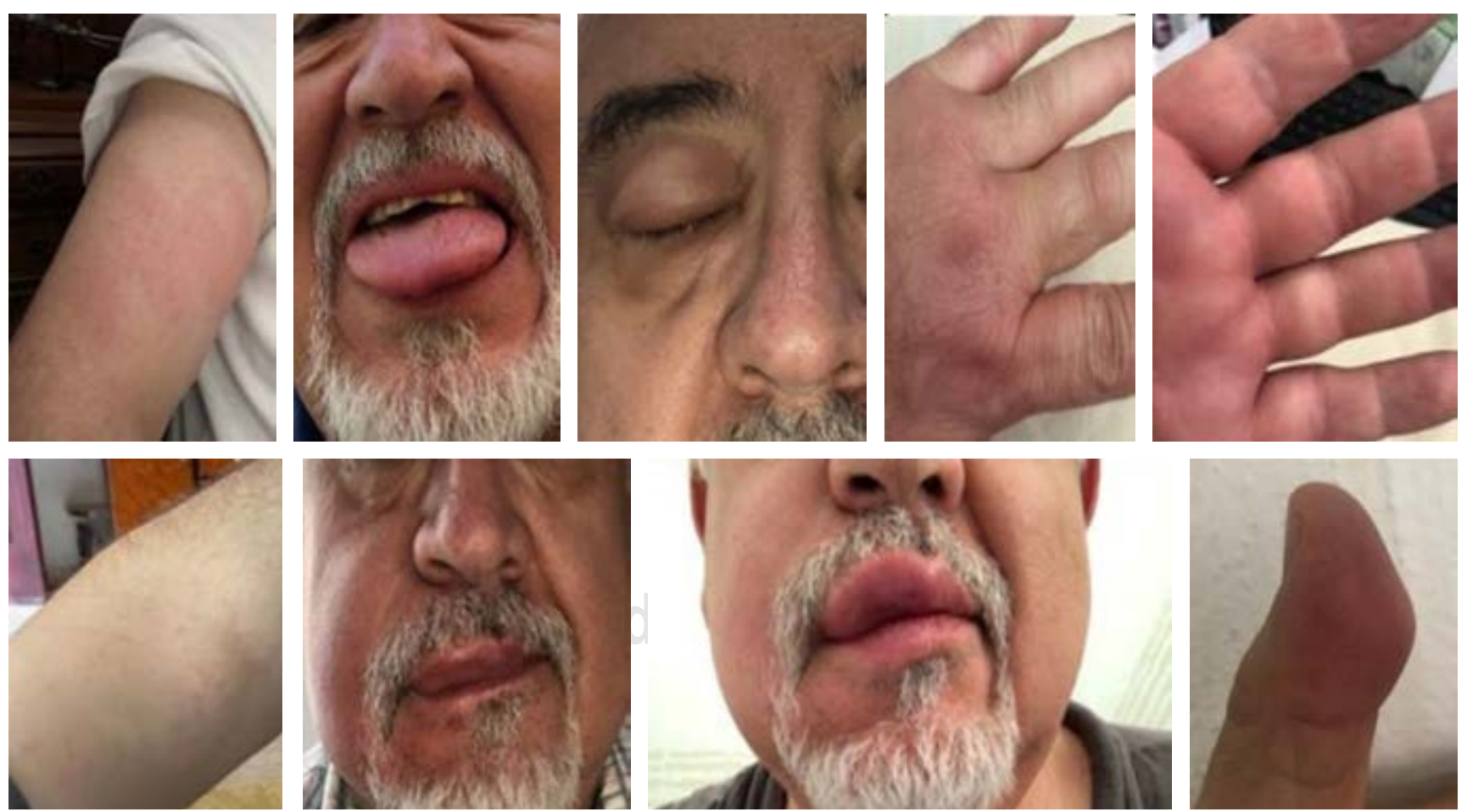

Figura 1: Paciente con urticaria y angioedema persistente por más de 3 semanas. Edema de lengua, párpados, labios y falanges, lesiones urticarianas en el resto del cuerpo en forma aislada. Vacuna pfizer (fotos enviadas por el paciente). 


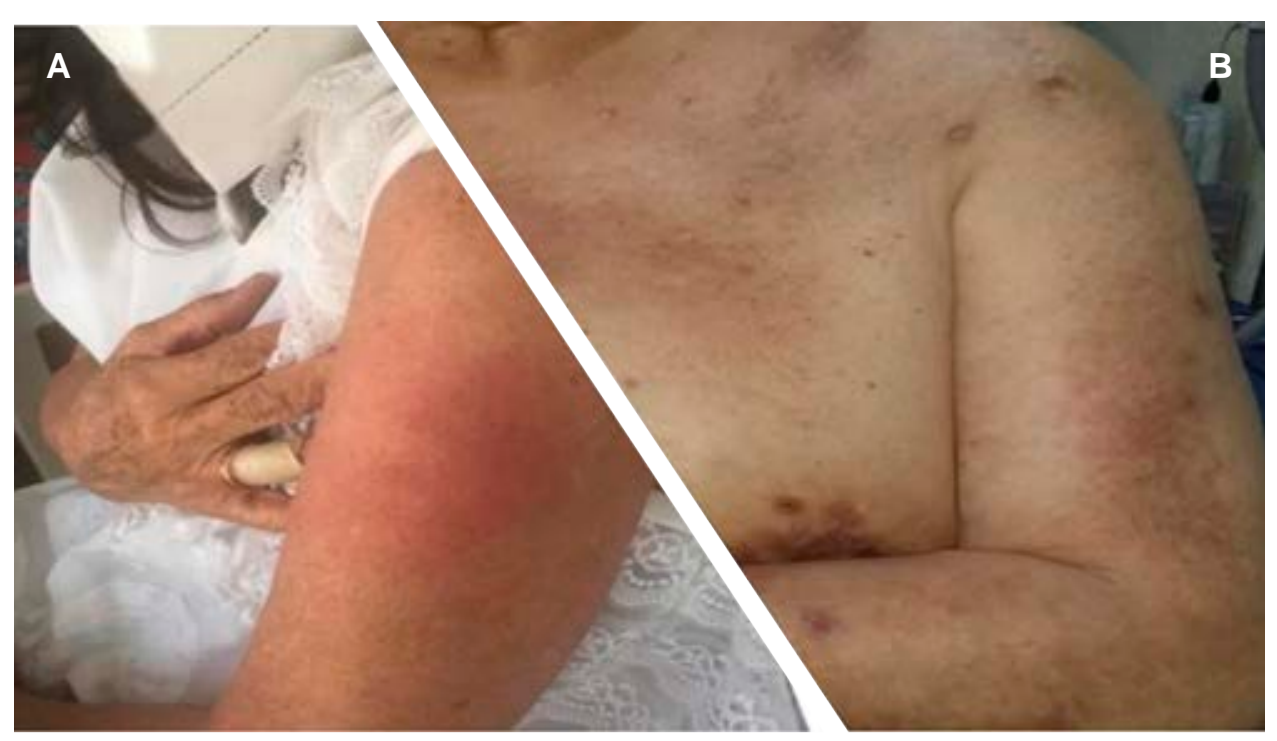

Figura 2:
A) Paciente con placa
indurada, eritematosa y pruriginosa que apareció a los 7 días de vacunación con vacuna moderna. B) Paciente con placa eritematosa y después pigmentada en brazo vacunado con vacuna pfizer 7 días después. Las lesiones se extendieron al tórax en forma zosteriforme.

\section{CASOS CLÍNICOS}

Caso 1. Masculino de 62 años de edad que recibió primera dosis de vacuna Pfizer el 12 de marzo de 2021, 15 días después de la vacuna inicia con edema de orejas, párpados, manos, en diferentes días durante un mes, aparición de ronchas diseminadas fugaces que cambian de sitio. Nunca manifestó dificultad ventilatoria. Fue tratado con diversos antihistamínicos con escasa respuesta. Después de la segunda dosis (16 abril de 2021) las lesiones se exacerbaron. Hasta el momento recibe fexofenadina y ebastina, pero la urticaria no ha sido controlada por completo (Figura 1).

Caso 2. Femenino de 74 años de edad que recibe vacuna Moderna en San Diego, California. Presenta inmediatamente astenia, dolor corporal generalizado, diaforesis nocturna de cinco a seis noches. Al noveno día inicia con una placa eritematosa, redondeada de bordes mal definidos de $9 \times 8 \mathrm{~cm}$ de diámetro en el sitio de la vacunación. Consultó por telemedicina y resolvió con hidrocortisona tópica al 1\%. La segunda dosis sólo presentó malestar general y excesiva fatiga (Figura 2).

Caso 3. Paciente masculino de 69 años de edad, conocido por presentar lesiones de prúrigo nodular de Hyde y liquen simple crónico. Había iniciado tratamiento con talidomida $100 \mathrm{mg}$ un día antes de la inoculación con vacuna Pfizer. Inicia inmediatamente con severa fatiga, somnolencia, febrícula y dolor corporal. Cinco días más tarde placa eritematosa que medía $8.3 \times 6 \mathrm{~cm}$ en el brazo vacunado que corría hacia la cara anterior del tórax con morfología zosteriforme. Se trató con mometasona tópica, resolviendo en seis días (Figura 2).

Caso 4. Masculino de 88 años de edad con antecedentes de hipertensión arterial sistémica, cardiopatía aterosclerosa, hiperplasia prostática y osteoporosis. Tomaba 19 medicamentos para sus problemas médicos (espironolactona, bumetanida, carvedilol, clopidogrel, trimetozidina, amiodarona, atorvastatina, verapamilo, tamsulosina, diosmina/ hesperidina, colecalciferol con calcio, aspirina, hierro, levotiroxina, teofilina, cloruro de potasio, esomeprazol, alprazolam). Todos los fármacos habían sido iniciados con más de tres meses de antelación al evento y el último había sido la amiodarona agregado seis semanas previas al incidente. Inicia 15 días después de haber sido inoculado con vacuna AstraZeneca. Presentaba dermatosis en ambas piernas con placas eritemato-purpúricas en forma simétrica al principio leticulares, en 12 horas formaron enormes placas violáceas que afectaban de la rodilla al antepié. El laboratorio reportó anemia de 12.9, leucocitos normales con eosinofilia leve, trombocitopenia moderada $(104,000)$, elevación de velocidad de sedimentación globular y proteína $\mathrm{C}$ reactiva ultrasensible, ANCA negativo, complemento y sus fracciones normales. Sin datos de afección renal o hepática atribuible al proceso inflamatorio. El tiempo de protrombina con actividad de $46 \%$. Activación de basófilos positiva para clopidogrel y verapamilo mayor de 60 y 42 para la amiodarona (Figura 3).

La biopsia de piel mostró una vasculitis leucocitoclástica con gran infiltrado inflamatorio en dermis y extravasación de eritrocitos. Se decidió suspensión de medicamentos no indispensables y tratamiento con glucocorticoides tópicos y sistémicos. La dermatosis resolvió en 12 días sin secuelas.

Caso 5. Masculino de 20 años sano, sin medicamentos, quien inicia dermatosis entre seis y siete días después de haber recibido vacuna Moderna. Consistía en una placa eritemato-edematosa en la cara interna del brazo vacunado, medía $15 \times 8 \mathrm{~cm}$, ardorosa y pruriginosa. Tres días después lesiones eritematosas bilaterales y simétricas en 
cara interna de ambos muslos con morfología "en blanco de tiro", además placas de 6 a $8 \mathrm{~mm}$ afectando dorso y palma de ambas manos. El laboratorio sólo mostró elevación de la PCR ultrasensible, descartamos la posibilidad de herpes simple. La biopsia de piel mostró importante espongiosis con formación de vesículas intraepidérmicas, infiltrado inflamatorio intenso de polimorfonucleares y linfocitos de predominio perivascular (Figura 4).

\section{DISCUSIÓN}

Las vacunas contra COVID-19 han demostrado causar reacciones sistémicas similares a la infección por el virus SARS-CoV-2, en general de leves a moderadas. El sitio de inoculación presenta dolor en más de $80 \%$ de los casos independientemente de la vacuna que se utilice. En la mayoría de los casos dura de 24 a 72 horas, a menos que se haya producido una complicación por la técnica de inyección (hematomas, neuritis por irritación del nervio circunflejo).

Las reacciones alérgicas graves a las vacunas se presentan con más frecuencia con la plataforma de ARN (Pfizer y Moderna). ${ }^{2-4}$ Según los estudios de fármaco vigilancia efectuados por el CDC (Center for Diseases Control) y la FDA en noviembre de 2020, después de haberse administrado las primeras dosis a 1'893,360 personas se reportaron 175 casos con severas reacciones alérgicas incluyendo anafilaxia. Estas reacciones ocurrieron en minutos a horas después de la vacunación con un promedio de 13 minutos (rango de dos a 150 minutos). Ocurrieron 11.1 eventos por millón de dosis, 21 de esos casos correspondieron a anafilaxia. ${ }^{2,4}$ El polietilenglicol (PEG) parece ser el blanco de las reacciones, ya que se encuentra como una nanopartícula lipídica que forma la concha del liposoma. Es una molécula que sirve como estabilizador del sistema de la vacuna, sus propiedades higroscópicas tienen capacidad inmunogénica. También el polisorbato 80 (polioxietileno-20 sorbitan) es sospechoso de contribuir a la anafilaxia. Hasta el día de hoy se han asociado seis casos con PEG y uno con polisorbato. ${ }^{4,7}$ Ambas moléculas y otros compuestos de las fórmulas pueden liberar IgE y activar los mastocitos y basófilos, los cuales expresan CD63, CD203c. Hay liberación de histamina, prostaglandinas, leucotrienos, triptasa, factor activador de plaquetas, heparina, proteasas, serotonina y citoquinas. También hay posibilidad de reacciones mediadas por liberación de complemento (pseudoalergia). Es importante detectar a los enfermos con antecedentes de reacciones a medicamentos, vacunas, PEG o polisorbato
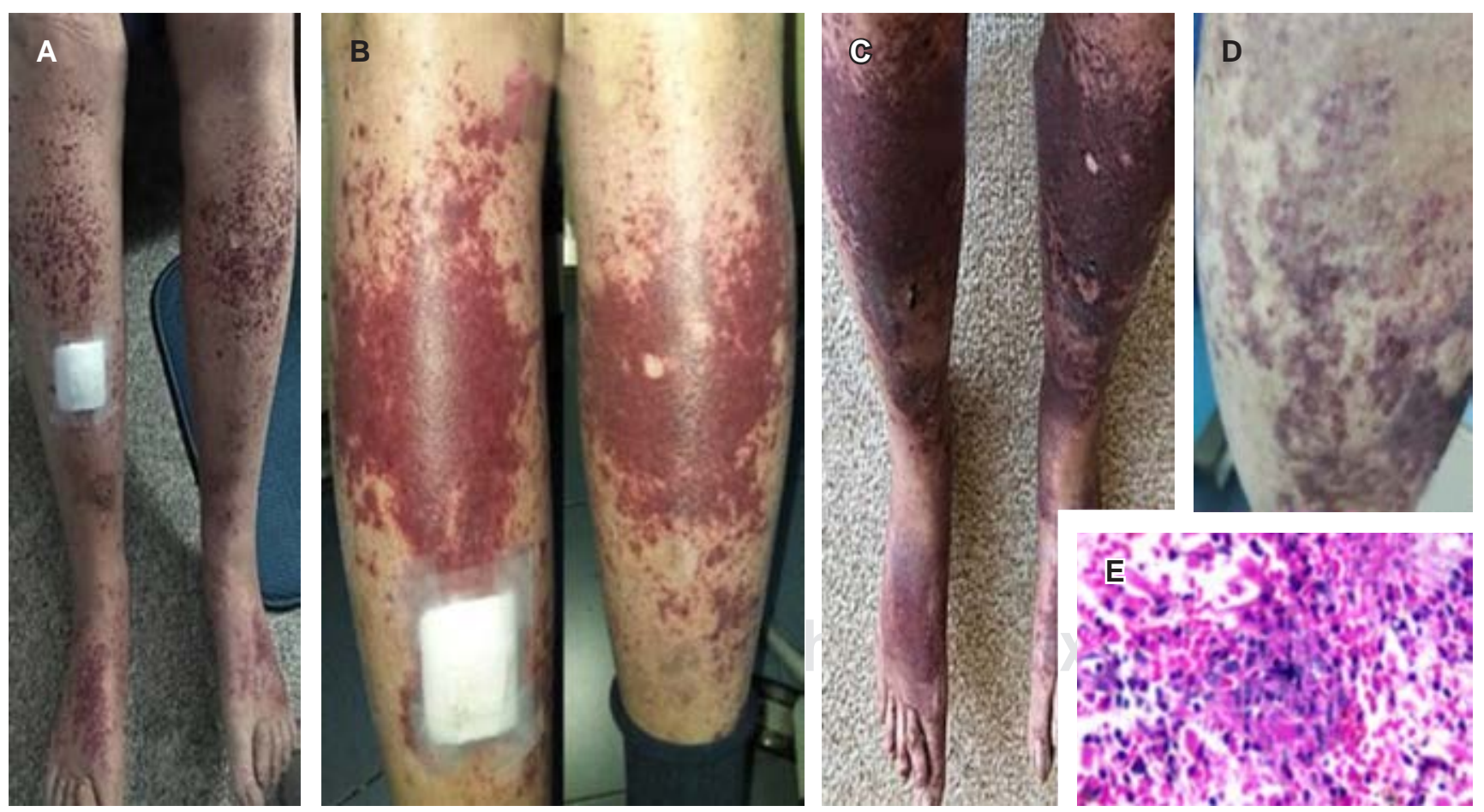

Figura 3: Paciente que presenta lesiones purpúricas progresivas en ambos miembros inferiores, las lesiones confluyen y forman grandes placas purpúricas en menos de 24 horas abarcando cara anterior de ambas piernas y antepiés. El paciente presentaba vasculitis leucocitoclástica con gran extravasación de eritrocitos. 

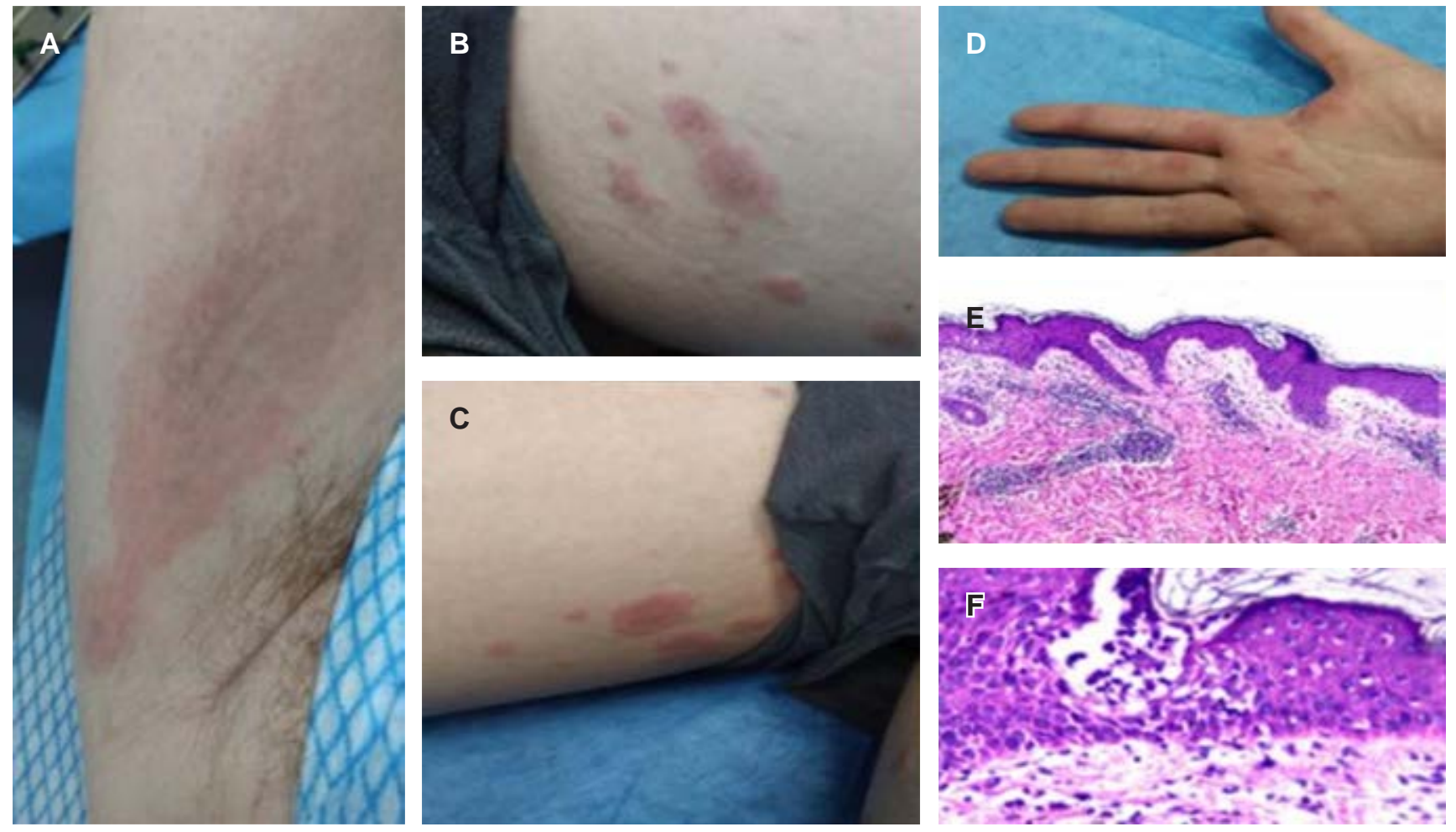

Figura 4: A-D) Paciente masculino de 20 años vacunado 5 días antes con vacuna moderna. Gran placa eritematosa que abarcaba la cara inferior del brazo vacunado, con centro oscuro y eritema pálido periférico. Además lesiones en "blanco de tiro" tipo urticariano bilaterales y simétricas en ingles y palmas de las manos. E y F) biopsia de piel con una epidermis espongiótica con formación de vesículas intraepidérmicas, infiltrado inflamatorio en dermis superficial y media con células inflamatorias de tipo linfoide con eosinófilos

y durante procedimientos médicos (endoscopias, procedimientos dentales), mastocitosis o reacción a la primera dosis de vacuna. Las vacunas de vector viral no contienen PEG, pero pueden contener polisorbato 80, también lo contienen múltiples medicamentos como esteroides parenterales, biológicos y vacunas para otras enfermedades, en pacientes alérgicos a alguno de estos fármacos puede producir reacción alérgica a la nueva inmunización. La premedicación con glucocorticoides puede ayudar antes de la vacunación. ${ }^{7-11}$

La urticaria se presenta en segundo lugar de las reacciones cutáneas. Nuestro paciente con urticaria y angioedema inició 15 días posteriores a la inoculación presentando angioedema en diferentes sitios, labios, orejas, párpados y dedos de las manos. Generalmente no tienen antecedentes. Es raro que la urticaria o angioedema asociados a la vacuna aparezcan en forma inmediata, casi todos aparecen después de dos días. La vacuna Moderna es la causa en $57 \%$ de los casos, el resto, como en este caso son secundarias a la administración de vacuna Pfizer. Llama la atención que no existen reportes de reacciones similares con las vacunas de manufactura china o rusa.

Los pacientes 2 y 3 representan las típicas reacciones tardías del tipo "brazo COVID" (eritema en placa en el sitio inoculado indurado y doloroso). La vacuna Moderna es la causa en $83 \%$ de los casos. Las mujeres las desarrollan en $90 \%$, 78\% de raza caucásica, $21 \%$ ocurrieron en la primera dosis, $63 \%$ después de la segunda, $16 \%$ en ambas dosis. Los exantemas y la eritromelalgia ocurren entre 72 horas y siete días después de la inoculación de vacuna, una vez más asociados a vacuna Moderna en 94\% de los casos. Los cuadros resuelven en forma espontánea o con un esteroide de baja potencia. ${ }^{10,11}$ La histología es similar a la encontrada en lesiones por enfermedad COVID-19: mínimos cambios epidérmicos con infiltrado perivascular, focal mixto de linfocitos y eosinófilos. ${ }^{10}$

El quinto caso desarrolló una forma mixta de reacción con una placa eritematosa que curiosamente apareció en la cara posterior del brazo, afectó las ingles en forma bilateral y con lesiones urticariformes "en blanco de tiro", había elementos máculo-papulares en ambas palmas. 
Histológicamente se encontró una dermatitis eccematoide y gran infiltrado inflamatorio perivascular por linfocitos pequeños y eosinófilos. ${ }^{11}$

Por último, el enfermo que desarrolló lesiones purpúricas después de la primera dosis con plataforma AstraZeneca es muy similar a los casos reportados por Lam y colaboradores, ${ }^{10}$ se inician entre tres y 14 días después de la inoculación, en estos casos la vacuna fue Pfizer. En ninguno de los dos casos reportados se mencionan los medicamentos que ingerían. Nuestro caso tomaba 19 distintos medicamentos, entre ellos, tratamiento para la hipertensión arterial y cardiopatía aterosclerosa, vitaminas y medicamentos para la hiperplasia prostática. Es muy probable que la génesis haya sido de tipo mixto, alérgico (hipersensibilidad de tipo III, por depósito de complejos inmunes) y toxicidad directa de algún medicamento o metabolito de ellos. Los anticoagulantes pueden tener un papel importante en la gran extravasación de eritrocitos que se encontró en la biopsia.

\section{CONCLUSIONES}

Todas las vacunas pueden provocar reacciones en la piel (Tabla 1). La plataforma Moderna las produce con más frecuencia y más a menudo en mujeres. Las reacciones más importantes en el orden de frecuencia son: "brazo COVID", urticaria y angioedema (no inmediatos), eccema o exantemas, eritromelalgia y misceláneos, donde podríamos clasificar dos de nuestros casos. Éste es el primer caso de púrpura por vasculitzis leucocitoclástica por vacuna AstraZeneca y un caso con reacción local inversa, lesiones inflamatorias en "blanco de tiro" y pápulas en palmas de las manos. La histología dependerá de la morfología de las lesiones. La diferencia entre una reacción a la vacuna o a los medicamentos es imposible de establecer, a menos que los medicamentos sean de reciente instalación (menos de un mes), inclusive pueden propiciar un cuadro clínico aparatoso. En caso de aparecer después de la primera dosis se debe valorar en forma adecuada la administración de la segunda, dependiendo de la gravedad del caso e inclusive se recomienda el uso profiláctico de esteroides y antihistamínicos.

Aún estamos aprendiendo de este tema. La gran mayoría de los reportes han sido publicados sólo en línea. Es interesante observar que aún no se hayan reportado reacciones similares con las vacunas de manufactura china o rusa, la razón es que estos países no han publicado sus resultados de fase III y sus efectos secundarios después de la aplicación masiva de sus productos, habrá que esperar observaciones posteriores.

Tabla 1: Casos de reacciones tardías a diversas vacunas contra COVID-19.
Edad (años)
Vacuna
Tipo de lesión
Peculiaridades

\begin{tabular}{|c|c|c|c|c|}
\hline Masculino & 62 & Pfizer (CDMX) & $\begin{array}{l}\text { Urticaria y angioedema } \\
\text { (evolución crónica: más } \\
\text { de seis semanas) }\end{array}$ & $\begin{array}{l}15 \text { días después primera dosis. } \\
\text { Exacerbación después de la segunda } \\
\text { dosis difícil control }\end{array}$ \\
\hline Femenino & 74 & $\begin{array}{c}\text { Moderna (San } \\
\text { Diego, California) }\end{array}$ & $\begin{array}{l}\text { Brazo COVID: gran placa } \\
\text { eritematosa } 8 \times 10 \mathrm{~cm} \\
\text { pruriginosa }\end{array}$ & $\begin{array}{l}\text { Ocho días después de la primera dosis } \\
\text { Gran ataque al estado general en } \\
\text { ambas dosis y severa fatiga en la } \\
\text { segunda }\end{array}$ \\
\hline Masculino & 69 & Pfizer (CDMX) & $\begin{array}{l}\text { Brazo COVID: placa eritematosa y } \\
\text { pigmentada, con extensión zosteriforme } \\
\text { al pecho }\end{array}$ & $\begin{array}{l}\text { Siete días después de la segunda } \\
\text { dosis y gran ataque al estado general } \\
\text { y fatiga }\end{array}$ \\
\hline Masculino & 88 & $\begin{array}{l}\text { AstraZeneca } \\
(\text { CDMX) }\end{array}$ & $\begin{array}{l}\text { Miembros inferiores, placas } \\
\text { purpúricas bilaterales y } \\
\text { simétricas, confluentes, afección de la } \\
\text { rodilla al antepié } \\
\text { Marcadores de inflamación }+ \text {, anca - y } \\
\text { complemento normal }\end{array}$ & $\begin{array}{l}15 \text { días después de la vacunación } \\
\text { tomaba } 19 \text { medicamentos entre ellos } \\
\text { aspirina y clopidogrel } \\
\text { Mecanismo inmunológico y tóxico } \\
\text { Biopsia: vasculitis leucocitoclástica con } \\
\text { gran extravasación de eritrocitos }\end{array}$ \\
\hline Masculino & 20 & $\begin{array}{l}\text { Moderna } \\
\text { (Houston) }\end{array}$ & $\begin{array}{l}\text { Cara inferior brazo vacunado: gran } \\
\text { placa urticariana de } \\
18 \times 10 \mathrm{~cm} \\
\text { Lesiones en "blanco de tiro" ambas } \\
\text { inglés y palmas de manos }\end{array}$ & $\begin{array}{l}\text { Siete días después de la vacuna } \\
\text { Biopsia: espongiosis y formación de } \\
\text { vesículas intraepidérmicas. infiltración } \\
\text { linfocítica y eosinofílica perivascular }\end{array}$ \\
\hline
\end{tabular}




\section{AGRADECIMIENTOS}

Agradecemos a todos los compañeros que nos remitieron sus casos con manifestaciones cutáneas para el presente reporte, al grupo de diseño de la sociedad médica del hospital ángeles del pedregal que configuró mil veces los artículos.

\section{REFERENCIAS}

1. Covid. [11 Mayo 202114.52 pm] live update: https://www. worldometers.info

2. US Department of Health and Human Services/Centers for Diseases Control and Prevention. Allergic Reactions Including Anaphyaxis after reciept of the first dose of Pfizer-BioNTech COVID- Cutaneous reactions reported after Moderna and Pfizer COVID-19 vaccination: a registry-based study of 414 cases COVID-19 Vaccine United States. MMWR. 2021; 70 (2): 46-51.

3. Kaur SP, Gupta V. COVID-19 vaccine: a comprehensive status report. Virus Res. 2020; 288: 198114. doi: org./10-1016/j. virusres.2020.198114.

4. Worm M, Bauer A, Wedi B, Treudler R, Pfuetzner W, Brockow K et al. Practical recommendations for the allergological risk assessment of the COVID-19 vaccination- a harmonized statement of allergy centers in Germany. Allergol Select. 2021; 5: 72-76. doi: 105414/ ALX02225E.

5. Ring J, Worm M, Wollenberg A, Thyssen JP, Jakob T, Kilmek L et al. Risk of severe allergic reactions to COVID-19 vaccines among patients with allergic skin diseases-practical recommendations. A position statement of ETFAD with external experts. J Eur Acad Dermatol Venereol. 2021; 35 (6): e362-e365. doi: 10.1111/jdv.17237.

6. McMahon DE, Amerson E, Rosenbach M, Lipoff JB, Moustafa D, Tyagi $A$ et al. Cutaneous reactions reported after Moderna and Pfizer COVID-19 vaccination: a registry-based study of 414 cases. J Am Acad Dermatol. 2021; 85 (1): 46-55. Available in: https://doi. org/10.1016/j.jaad.2021.03.092

7. Klimek L, Novak N, Cabanillas B, Jutel M, Bousquet J, Akdis CA. Allergenic components of the mRNA-1273 vaccine for COVID-19: possible involvement of polyethylene glycol and IgG-mediated complement activation. Allergy. 2021;3:10.1111/all.14794. doi: 10.1111/JOCD14794.

8. Johnston MS, Galan A, Watsky KL, Little AJ. Delayed localized hypersensitivity reactions to the Moderna COVID-19 vaccine: a case series. JAMA Dermatol. 2021; 157 (6): 716-720. doi: 10.1001jamadermatol.20211214.

9. Tammaro A, Magri F, Chello C. Local skin reaction to the AZD1222 vaccine in patient who survived COVID-19. J Cosmet Dermatol. 2021. Available in: https://doi.org/10.1111/jocd.14205

10. Lam M, Egail M, Bedlow AJ, Tso S. Ribonucleic acid (RNA) COVID-19 vaccine associated cutaneous adverse drug events: a case series of two patients. Clin Exp Dermatol. 2021. Available in: https://doi. org/10.1111/ced.14673021

11. Banerji A, Wickner PG, Saff R, Stone CA, Robinson LB, Long AA et al. mRNA Vaccines to prevent COVID-19 disease and reported allergic reactions: current evidence and suggested approach. J Allerg Clin Immunol Pract. 2021; 9 (4): 1423-1437. Available in: https://doi. org/10.1016/j.jaip.2020.12.047

Conflicto de intereses: Sin conflicto de intereses. 